\title{
KAJIAN KEBETAHAN MAHASISWA DALAM LINGKUNGAN KAMPUS Studi Kasus: Kampus ITSB - Cikarang
}

\author{
Kukuh Rizki Satriaji \\ Program Studi Desain Interior, Fakultas Teknik dan Desain, Institut Teknologi dan Sains Bandung \\ Cikarang, Bekasi \\ Email: kukuh.satriaji@yahoo.com
}

\begin{abstract}
Abstrak
Dalam kesehariannya manusia melakukan interaksi dengan ruang dan lingkungan. Faktor fisik dan non fisik dari sebuah ruang akan mempengaruhi perasaan dan pengalaman seseorang berada di dalamnya. Kondisi ruang yang baik akan membuat seseorang merasa betah, sedangkan kondisi ruang yang tidak baik akan membuat seseorang merasa tidak betah. Lingkungan kampus ITSB merupakan salah satu fasilitas akademik yang di dalamnya digunakan oleh beberapa pengguna, yaitu mahasiswa, dosen, staf dan lainnya. Di dalamnya sangat memungkinkan terjadinya interaksi antara manusia dengan manusia dan manusia dengan ruang/bangunan agar kegiatan dapat berlangsung dengan baik. Penelitian ini bertujuan untuk menelaah dan menemukan faktor-faktor yang menyebabkan pengguna kampus, terutama mahasiswa, merasa betah di dalam Kampus ITSB. Mahasiswa aktif dari berbagai angkatan dipilih sebagai subyek utama penelitian. Definisi kebetahan dari sudut pandang mahasiswa akan dibandingkan dengan definisi kebetahan dalam konteks ruang interior sehingga dapat memberikan pemahaman terhadap interaksi manusia terhadap lingkungan (ruang).
\end{abstract}

Kata kunci: kebetahan, interaksi, mahasiswa

\begin{abstract}
Title: The Study of The Student Comfortability In Campus Environment Case Study: ITSB Campus, Cikarang

The old downtown area of Banda Aceh holds high historical value, as evidenced by the many historic relics that still survive as a historic object in the region. The existence of these ancient artifacts can complement the historical narrative as well as the authentic proof of the identity of the city of Banda Aceh. The central area of Banda Aceh requires interesting public spaces to make the existence of these historic assets more prominent as an element of the attraction of this historic area. This study aims to strengthen the identity of the downtown area of Banda Aceh through an architectural design concept in a potential public corridor that has not been optimally utilized. The idea is to assemble historic spaces in this corridor to make it easier and convenient for pedestrians to access. This research is done by recording visual image of open space in public corridor area to capture visual picture and to know physical quality of public spaces in the location. Increased visual accentuation in the public corridors of the downtown area of Banda Aceh can form visual sequences that provide different spatial experiences. The experience of this space arises from the historical space-themed space phases supported by the gradual display of space elements. The key to success in strengthening the identity of this corridor is the selection of the design of appropriate elements of space, in accordance with the character of space that can represent the values and historical identity of the region.
\end{abstract}

Keywords: place attachment, interaction, students 


\section{Pendahuluan}

Manusia dalam melakukan aktivitas akan berinteraksi dengan ruang, baik ruang formal maupun ruang informal. Agar aktivitas yang dilakukan dapat berjalan dengan baik maka diperlukan suatu studi mengenai kebetahan terhadap ruang. Sebuah ruang terbentuk dari tiga unsur yaitu fisik bangunan, aktivitas di dalamnya dan makna (Montgomery, 1998). Unsur fisik yang dimaksud adalah elemen pembentuk ruang yaitu lantai, dinding dan langit-langit serta furnitur di dalamnya; Aktivitas berkaitan dengan kegiatan yang terjadi.; Sedangkan makna berkaitan dengan kondisi psikologi dan perasaan yang bersifat subyektif akibat proses dan pengalaman yang dialami ketika seseorang berada di dalam ruang.

Kebetahan didefinisikan sebagai kondisi psikologis dimana manusia merasa nyaman dan puas pada suatu tempat sehingga senang untuk tinggal berlama-lama pada tempat itu (Rachman \& Kusuma, 2014). Kondisi betah tersebut dapat berhubungan dengan faktor fisik maupun non-fisik sebuah ruang/lingkungan.

Salah satu fasilitas umum yang membutuhkan kenyamanan yang baik adalah kampus sebagai sarana akademik bagi mahasiswa. Kampus Institut Teknologi dan Sains Bandung (ITSB), merupakan tempat terjadinya berbagai aktivitas, baik formal seperti perkuliahan, sidang, workshop, seminar, maupun informal seperti diskusi, kerja kelompok, kegiatan unit dan lainnya. Berbagai aktivitas tersebut membutuhkan suatu kondisi lingkungan/ ruang yang baik agar dapat berjalan dengan baik. Mahasiswa dipilih sebagai subyek penelitian utama dengan pertimbangan bahwa selama kurang lebih 4 tahun akan berada dalam lingkungan kampus dan akan banyak berinteraksi di dalamnya. Lingkungan kampus yang baik akan memberikan semangat pada mahasiswa untuk semakin giat beraktivitas dan berinteraksi sosial.

Tujuan dari penelitian ini adalah untuk mengetahui definisi kebetahan menurut mahasiswa terhadap kondisi lingkungan kampus yang ideal, terutama di ITSB serta faktor yang menyebabkan terjadinya hubungan kebetahan antara mahasiswa terhadap lingkungan dalam kampus ITSB. Kebetahan yang terjadi diharapkan akan mampu meningkatkan produktivitas mahasiswa di dalam kampus.

\section{Metode Penelitian}

Penelitian ini menggunakan pendekatan kualitatif eksploratif (Creswell, 2008) dengan tujuan untuk mengetahui faktor-faktor yang menyebabkan mahasiswa merasa betah berada di dalam kampus. Beberapa tahapan yang dilakukan dalam penelitian ini antara lain, tahap pengumpulan data, tahap analisis dan kesimpulan (interpretasi data analisis). Pengumpulan data dilakukan dalam bentuk kuesioner dan wawancara langsung yang dilakukan selama bulan september sampai dengan november 2016 di sekitar Kampus ITSB. Responden yang dipilih dengan metode non-random sampling (Kumar, 2005) dengan subyek utama adalah mahasiswa ITSB yang terdaftar aktif. 


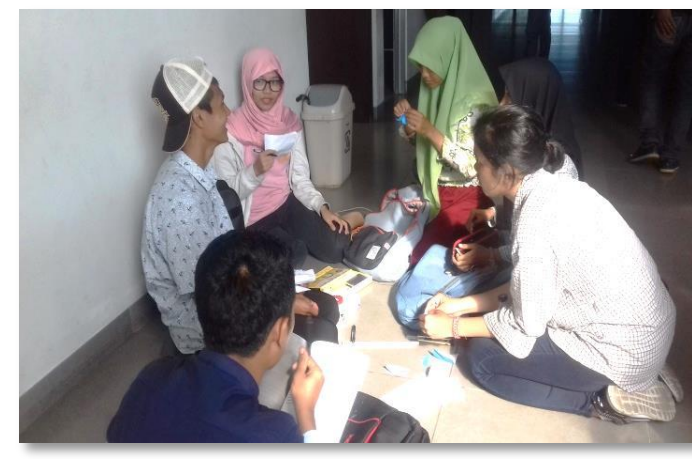

Gambar 1. Proses pengumpulan data melalui kuesioner dan wawancara

Sumber: Dokumentasi penulis, 2016

Metode analisis data yang digunakan adalah dengan analisis makna (content analysis) yang digunakan untuk memahami dan menganalisis hasil jawaban responden secara obyektif dan sistematis. Tujuannya adalah untuk mengetahui, mengelompokkan dan mengidentifikasi jawaban yang diberikan oleh responden terkait dengan pertanyaan mengenai kebetahan yang diberikan (Rachman, 2014). Software yang digunakan adalah microsoft excel untuk membantu dalam menyusun tabel dan mengolah data. Tahap analisis dilakukan dengan tiga tahap (Creswell dalam Rachman, 2014), yaitu:

a. Tahap open coding, merupakan tahap identifikasi kata kunci dari jawaban yang diberikan oleh responden terkait dengan kebetahan dalam lingkungan kampus;

b. Tahap axial coding, merupakan tahap pembuatan kategori dari kata kunci yang telah ditemukan sebelumnya.

Tahap selective coding, merupakan tahap analisis hubungan antara kategori dan hasil penghitungan frekuensi.

\section{Kajian Teori}

Kajian kebetahan pada awalnya merupakan bagian dari kajian fenomenologi (Altman, 1992) yang menekankan pada pengalaman subyektif yang unik berkaitan dengan perilaku dalam lingkungan. Kebetahan juga dapat didefinisikan sebagai hubungan yang terbentuk antara individu dengan tempat-tempat yang spesifik (Hidalgo dan Hernadez dalam Ujang, 2010). Kebetahan merupakan hasil interaksi dua arah antara pengamat dan kondisi lingkungan itu sendiri (Lynch, 1960). Istilah kebetahan akan selalu berkaitan dengan konteks tempat dan ruang (place), dimana seseorang akan merasa terikat secara emosional dan kultural.

Bangunan merupakan sebuah lingkungan binaan yang dibuat dengan tujuan khusus yang mampu mengakomodasi aktivitas manusia. Lingkungan binaan, termasuk di dalamnya ruang interior merupakan perpaduan dari berbagai elemenelemen fisik bangunan seperti dinding, lantai, furnitur, pencahayaan, penghawaan, dll. Kualitas fisik sebuah ruang interior akan mempengaruhi derajat kebetahan pengguna di dalamnya. Dari beberapa teori dan definisi kebetahan yang sudah diperoleh sebelumnya, telah disusun 22 indikator yang akan digunakan untuk menilai tingkat kebetahan pengguna dalam sebuah ruang (lihat tabel 1).

Tabel 1. Komponen dan indikator ruang yang akan digunakan dalam kajian kebetahan

\begin{tabular}{lll}
\hline Komponen & Indikator & Keterangan \\
\hline \multirow{4}{*}{$\begin{array}{l}\text { Fisik } \\
\text { Bangunan }\end{array}$} & \multirow{2}{*}{ Aksesibilitas } & Lokasi \\
\cline { 2 - 3 } & & Akses \\
\cline { 2 - 3 } & \multirow{2}{*}{ Fasilitas } & Layout \\
& & Fasilitas duduk \\
& & Stop kontak \\
& & Internet \\
\hline
\end{tabular}




\begin{tabular}{|c|c|c|}
\hline & & Penghawaan \\
\hline & \multirow{3}{*}{ Legibilitas } & Signage \\
\hline & & Pemandangan \\
\hline & & Vegetasi \\
\hline \multirow{5}{*}{ Aktivitas } & \multirow{2}{*}{ Formal } & Kuliah \\
\hline & & Diskusi \\
\hline & \multirow{3}{*}{ Informal } & $\begin{array}{l}\text { Kegiatan } \\
\text { Himpunan }\end{array}$ \\
\hline & & $\begin{array}{l}\text { Makan dan } \\
\text { minum }\end{array}$ \\
\hline & & Ngobrol \\
\hline \multirow{6}{*}{ Makna } & \multirow{2}{*}{ Aman } & Terbuka \\
\hline & & Terlindung \\
\hline & \multirow{2}{*}{ Nyaman } & Sejuk \\
\hline & & Tenang \\
\hline & \multirow{2}{*}{ Fungsi } & Fasilitas sesuai \\
\hline & & Kejelasan fungsi \\
\hline
\end{tabular}

\section{Karakteristik Responden}

Data yang diperoleh dari penyebaran kuesioner dan wawancara terdapat sejumlah 59 responden, 39 responden laki-laki, 18 responden perempuan dan 2 responden tidak memberikan keterangan jenis kelamin dengan jarak usia 17-22 tahun (lihat diagram 1).

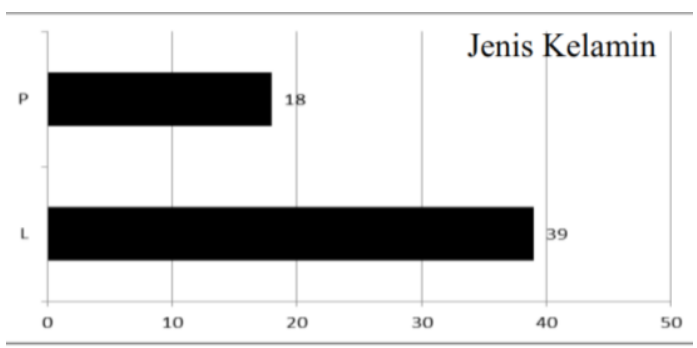

Diagram 1. Histogram jenis kelamin responden

Mahasiswa yang menjadi responden terbagi menjadi 4 angkatan aktif yaitu angkatan 2013 (17 responden), 2014 (8 responden), 2015 (7 responden) dan 2016 (27 responden) (lihat diagram 2). 4 perwakilan angkatan ini dianggap mampu mewakili populasi ITSB secara umum.

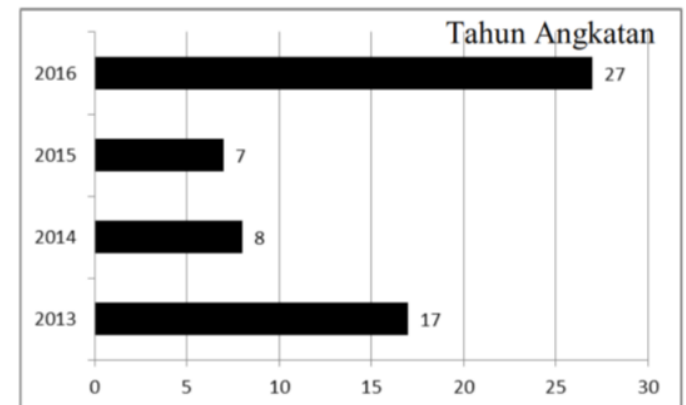

Diagram 2. Histogram tahun angkatan kuliah responden

\section{Analisis dan Interprestasi Data}

\section{Lama dan Motivasi Mahasiswa} Berada di Kampus

Dari hasil kuesioner dan wawancara dapat diketahui bahwa frekuensi mahasiswa berada di dalam kampus paling banyak adalah 20-30 jam (28 responden), <20 jam (24 responden) dan $>30$ jam (7 responden) (lihat diagram 3 ).

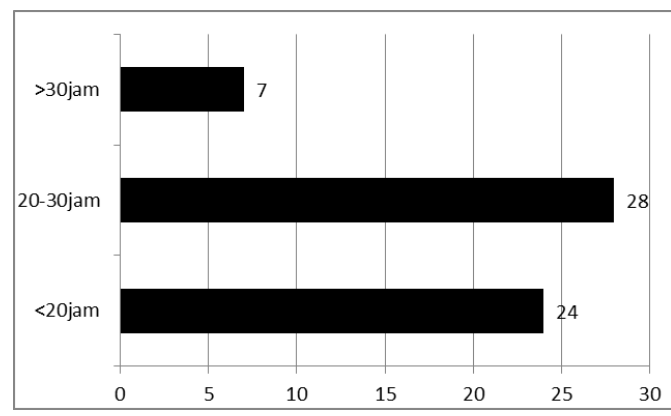

Diagram 3. Frekuensi lama mahasiswa berada di dalam kampus

Dari data di yang diperoleh, bila dikaitkan dengan jumlah rata-rata sks yang diambil oleh mahasiswa dalam satu semester yaitu sekitar 18-21 sks (data kurikulum ITSB), maka waktu yang dihabiskan mahasiswa dalam kampus kurang lebih sekitar 18-20 jam (24 responden) untuk mengikuti perkuliahan. Hal ini masih tergolong normal, namun setelah perkuliahan berakhir mahasiswa tidak memiliki alasan untuk diam di kampus dan cenderung pergi meninggalkan kampus 
dan dianggap memiliki tingkat kebetahan rendah di dalam kampus. Untuk frekuensi 20-30 jam (28 responden) dianggap memiliki tingkat kebetahan normal/baik. Sedangkan untuk frekuensi di atas 30 jam (7 responden) merupakan mahasiswa yang memiliki tingkat kebetahan tinggi di dalam kampus.

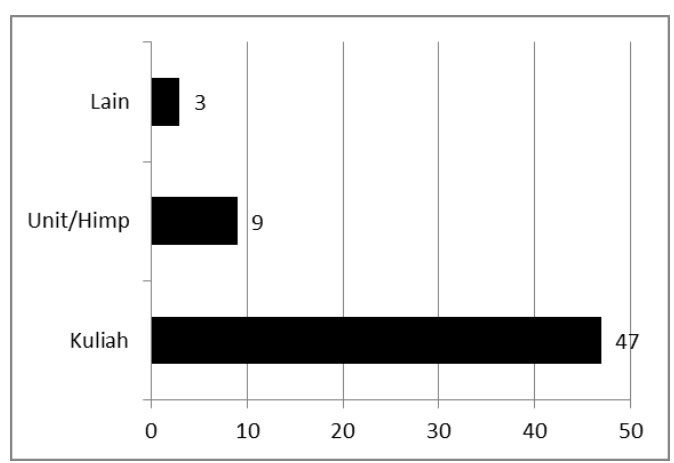

Diagram 4. Frekuenasi alasan kegiatan mahasiswa dalam kampus

Berdasarkan hasil kuesioner dan wawancara mengenai alasan kegiatan mahasiswa di dalam kampus, alasan utamanya adalah kuliah responden), mengikuti unit/himpunan (9 responden), dan lainnya (3 responden) (lihat diagram 4). Mengikuti kuliah menjadi motivasi utama mahasiswa untuk berada di lingkungan kampus, beberapa alasannya antara lain karena mahasiswa menganggap tugas utama mereka adalah belajar selain itu faktor penyebab lainnya adalah jarak kampus yang jauh dari tempat tinggal mahasiswa sehingga sulit untuk melakukan kegiatan di luar jam kuliah.

\section{Area Favorit Mahasiswa di Dalam Kampus dan Alasannya}

Area favorit dalam penelitian ini diasumsikan sebagai area yang memiliki tingkat kebetahan paling tinggi di dalam Kampus ITSB. Dari data kuesioner (lihat diagram 5) dapat diketahui bahwa area favorit mahasiswa dalam Kampus ITSB adalah di kelas (20 responden), kantin (18 responden), area selasar (13 responden) dan area meja batu (9 responden). Area-area tersebut terbagi menjadi area yang bersifat privat (kelas) dan area yang bersifat publik dan bisa digunakan oleh responden ketika tidak ada kegiatan formal berlangsung (kantin, selasar, meja batu).

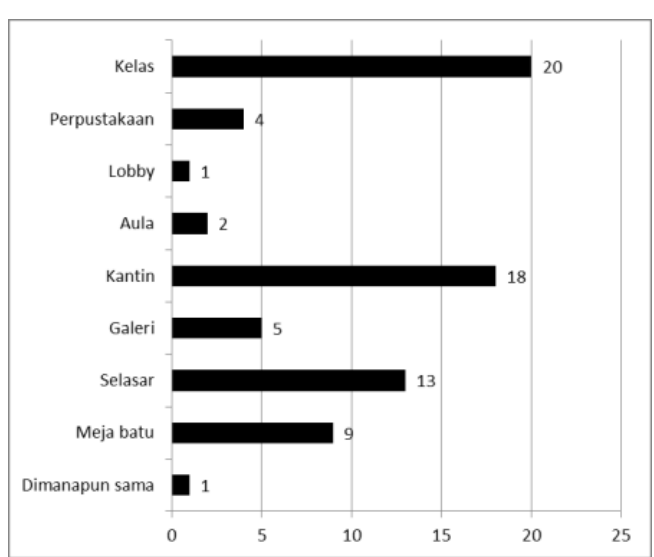

Diagram 5. Frekuensi area favorit dalam kampus
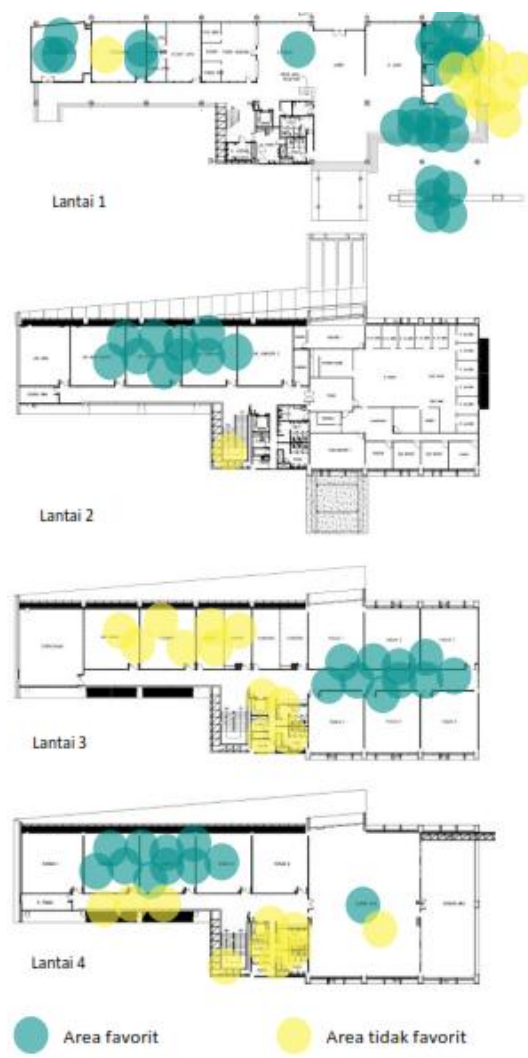

Gambar 2. Persebaran lokasi favorit dan tidak favorit mahasiswa 
Dengan membandingkan frekuensi persebaran lokasi favorit dan tidak favorit mahasiswa terhadap Kampus ITSB (lihat gambar 2), warna biru menggambarkan area dalam kampus yang difavoritkan untuk berlama-lama sedangkan warna kuning menggambarkan area dalam kampus yang tidak difavoritkan untuk berlamalama berada di dalamnya.

Ruang kelas (lihat gambar 3) menjadi area paling favorit di ITSB karena memiliki pencahayaan yang cukup, baik pencahayaan alami, dengan banyaknya bukaan sehingga cahaya matahari dapat masuk, maupun pencahayaan buatan (lampu). Selain itu ruang kelas dilengkapi juga dengan pengkondisian udara buatan (AC) karena suhu udara di bekasi yang cukup panas, AC digunakan untuk mengatur suhu ruang agar kondisi ruang kelas menjadi nyaman. Terakhir adalah terdapatnya furnitur standar perkuliahan (meja dan kursi) untuk melangsungkan perkuliahan. Sehingga dapat disimpulkan bahwa ruang kelas merupakan area dalam kampus dengan fasilitas paling lengkap.

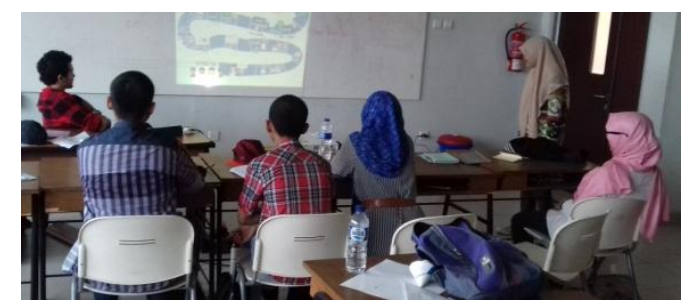

Gambar 3. Suasana kelas ITSB

Sumber: Dokumentasi penulis, 2016

Tabel 2. Analisis indikator kebetahan ruang kelas

\begin{tabular}{llll}
\hline Komponen & Indikator & \multicolumn{2}{c}{ Keterangan } \\
\hline \multirow{4}{*}{$\begin{array}{l}\text { Fisik } \\
\text { Bangunan }\end{array}$} & \multirow{3}{*}{ Fksesibilitas } & Lokasi & $\mathrm{V}$ \\
\cline { 3 - 4 } & & Akses & $\mathrm{V}$ \\
\cline { 3 - 4 } & & Layout & $\mathrm{V}$ \\
\cline { 3 - 4 } & & $\begin{array}{l}\text { Fasilitas } \\
\text { duduk }\end{array}$ & $\mathrm{V}$ \\
\cline { 3 - 4 } & & Stop kontak & $\mathrm{V}$ \\
\cline { 3 - 4 } & & Internet & $\mathrm{V}$ \\
\cline { 3 - 4 } & & Pencahayaan & $\mathrm{V}$ \\
\cline { 3 - 4 } & & Penghawaan & $\mathrm{V}$ \\
\cline { 2 - 4 } & Legibilitas & Signage & $\mathrm{V}$ \\
\hline
\end{tabular}

\begin{tabular}{|c|c|c|c|}
\hline & & Pemandangan & V \\
\hline & & Vegetasi & - \\
\hline \multirow{5}{*}{ Aktivitas } & \multirow{2}{*}{ Formal } & Kuliah & $\mathrm{V}$ \\
\hline & & Diskusi & $\mathrm{V}$ \\
\hline & \multirow{3}{*}{ Informal } & $\begin{array}{l}\text { Kegiatan } \\
\text { Himpunan }\end{array}$ & - \\
\hline & & $\begin{array}{l}\text { Makan dan } \\
\text { minum }\end{array}$ & $\mathrm{V}$ \\
\hline & & Ngobrol & $\mathrm{V}$ \\
\hline \multirow{6}{*}{ Makna } & \multirow{2}{*}{ Aman } & Terbuka & - \\
\hline & & Terlindung & $\mathrm{V}$ \\
\hline & \multirow{2}{*}{ Nyaman } & Sejuk & $\mathrm{V}$ \\
\hline & & Tenang & $\mathrm{V}$ \\
\hline & \multirow{2}{*}{ Fungsi } & $\begin{array}{l}\text { Fasilitas } \\
\text { sesuai }\end{array}$ & $\mathrm{V}$ \\
\hline & & $\begin{array}{l}\text { Kejelasan } \\
\text { fungsi }\end{array}$ & $\mathrm{V}$ \\
\hline
\end{tabular}

Ruang kelas memenuhi 19 indikator kebetahan (86,3 \%) terhadap ruang, (lihat tabel 2) sehingga responden banyak yang memilih ruang kelas sebagai area yang memiliki tingkat kebetahan paling tinggi.

Area kedua adalah kantin ITSB yang berada di lantai satu, merupakan area semi terbuka tanpa pintu sehingga udara dan cahaya matahari dapat masuk dengan baik. Area ini dilengkapi dengan meja dan kursi makan standar. Area ini biasa digunakan oleh mahasiswa untuk menunggu ketika jam istirahat maupun jam pergantian mata kuliah.

Tabel 3. Analisis indikator kebetahan kantin ITSB

\begin{tabular}{|c|c|c|c|}
\hline Komponen & Indikator & Keteran & \\
\hline \multirow{11}{*}{$\begin{array}{l}\text { Fisik } \\
\text { Bangunan }\end{array}$} & \multirow{3}{*}{ Aksesibilitas } & Lokasi & $\mathrm{V}$ \\
\hline & & Akses & $\mathrm{V}$ \\
\hline & & Layout & $\mathrm{V}$ \\
\hline & \multirow{5}{*}{ Fasilitas } & $\begin{array}{l}\text { Fasilitas } \\
\text { duduk }\end{array}$ & $\mathrm{V}$ \\
\hline & & Stop kontak & $\mathrm{V}$ \\
\hline & & Internet & - \\
\hline & & Pencahayaan & $\mathrm{V}$ \\
\hline & & Penghawaan & $\mathrm{V}$ \\
\hline & \multirow{3}{*}{ Legibilitas } & Signage & - \\
\hline & & Pemandangan & $\mathrm{V}$ \\
\hline & & Vegetasi & $\mathrm{V}$ \\
\hline \multirow{5}{*}{ Aktivitas } & \multirow{2}{*}{ Formal } & Kuliah & - \\
\hline & & Diskusi & $\mathrm{V}$ \\
\hline & \multirow{3}{*}{ Informal } & $\begin{array}{l}\text { Kegiatan } \\
\text { Himpunan }\end{array}$ & $\mathrm{V}$ \\
\hline & & $\begin{array}{l}\text { Makan dan } \\
\text { minum }\end{array}$ & $\mathrm{V}$ \\
\hline & & Ngobrol & V \\
\hline \multirow{3}{*}{ Makna } & \multirow{2}{*}{ Aman } & Terbuka & $\mathrm{V}$ \\
\hline & & Terlindung & $\mathrm{V}$ \\
\hline & Nyaman & Sejuk & $\overline{\mathrm{V}}$ \\
\hline
\end{tabular}




\begin{tabular}{lll}
\hline & Tenang & - \\
\cline { 2 - 3 } Fungsi & $\begin{array}{l}\text { Fasilitas } \\
\text { sesuai }\end{array}$ & $\mathrm{V}$ \\
\cline { 2 - 3 } & $\begin{array}{l}\text { Kejelasan } \\
\text { fungsi }\end{array}$ & $\mathrm{V}$ \\
\hline
\end{tabular}

Area kantin memenuhi 18 indikator kebetahan $(81,1 \%)$ terhadap ruang, (lihat tabel 3) sehingga responden memilih kantin sebagai area yang memiliki tingkat kebetahan kedua tertinggi.

Area ketiga adalah selasar ITSB merupakan area semi terbuka dengan perbedaan level lantai yang cukup tinggi sehingga tercipta undakan pada lantai. Area ini biasa digunakan oleh mahasiswa untuk bersantai dan bersosialisasi (lihat gambar 4)

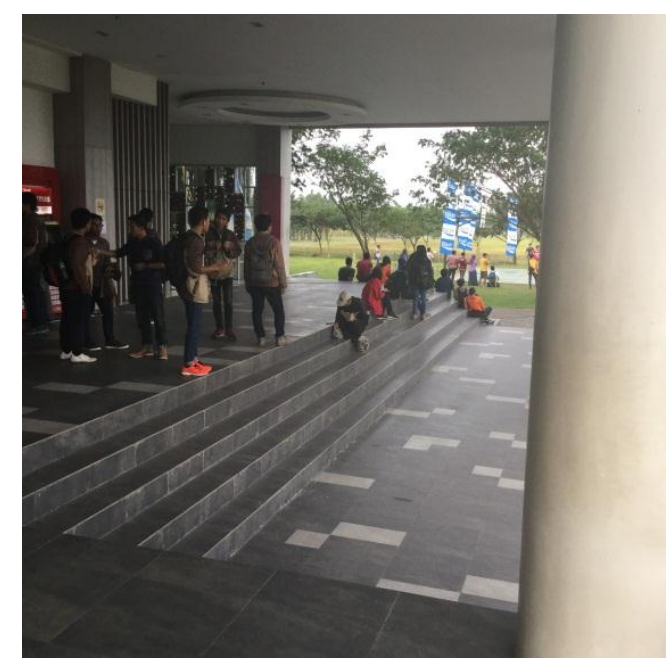

Gambar 4. Area selasar ITSB

Sumber: Dokumentasi penulis, 2016

Tabel 4. Analisis indikator kebetahan selasar ITSB

\begin{tabular}{|c|c|c|c|}
\hline Komponen & Indikator & \multicolumn{2}{|c|}{ Keterangan } \\
\hline \multirow{11}{*}{$\begin{array}{l}\text { Fisik } \\
\text { Bangunan }\end{array}$} & Aksesibilitas & Lokasi & $\mathrm{V}$ \\
\hline & & Akses & $\mathrm{V}$ \\
\hline & & Layout & $\mathrm{V}$ \\
\hline & Fasilitas & $\begin{array}{l}\text { Fasilitas } \\
\text { duduk }\end{array}$ & - \\
\hline & & Stop kontak & - \\
\hline & & Internet & - \\
\hline & & Pencahayaan & $\mathrm{V}$ \\
\hline & & Penghawaan & $\mathrm{V}$ \\
\hline & Legibilitas & Signage & - \\
\hline & & Pemandangan & $\mathrm{V}$ \\
\hline & & Vegetasi & $\mathrm{V}$ \\
\hline \multirow{3}{*}{ Aktivitas } & Formal & Kuliah & - \\
\hline & & Diskusi & $\mathrm{V}$ \\
\hline & Informal & $\begin{array}{l}\text { Kegiatan } \\
\text { Himpunan }\end{array}$ & V \\
\hline
\end{tabular}

\begin{tabular}{|c|c|c|c|}
\hline & & $\begin{array}{l}\text { Makan dan } \\
\text { minum }\end{array}$ & $\mathrm{V}$ \\
\hline & & Ngobrol & V \\
\hline \multirow{6}{*}{ Makna } & Aman & Terbuka & $\mathrm{V}$ \\
\hline & & Terlindung & - \\
\hline & Nyaman & Sejuk & $\mathrm{V}$ \\
\hline & & Tenang & - \\
\hline & Fungsi & $\begin{array}{l}\text { Fasilitas } \\
\text { sesuai }\end{array}$ & - \\
\hline & & $\begin{array}{l}\text { Kejelasan } \\
\text { fungsi }\end{array}$ & $\mathrm{V}$ \\
\hline
\end{tabular}

Area selasar memenuhi 14 indikator kebetahan $(63,6 \%)$ terhadap ruang, (lihat tabel 4) sehingga responden memilih selasar sebagai area yang memiliki tingkat kebetahan ketiga tertinggi.

Area keempat adalah meja batu ITSB merupakan area luar ruang (outdoor) yang dapat digunakan sebagai tempat menunggu, mengerjakan tugas dan bersosialisasi. Karena bersifat terbuka maka intensitas penggunaannya sangat dipengaruhi oleh faktor cuaca.

Tabel 5. Analisis indikator kebetahan meja batu ITSB

\begin{tabular}{|c|c|c|c|}
\hline Komponen & Indikator & Keteran & \\
\hline \multirow{11}{*}{$\begin{array}{l}\text { Fisik } \\
\text { Bangunan }\end{array}$} & Aksesibilitas & Lokasi & $\mathrm{V}$ \\
\hline & & Akses & $\mathrm{V}$ \\
\hline & & Layout & $\mathrm{V}$ \\
\hline & Fasilitas & $\begin{array}{l}\text { Fasilitas } \\
\text { duduk }\end{array}$ & - \\
\hline & & Stop kontak & - \\
\hline & & Internet & - \\
\hline & & Pencahayaan & $\mathrm{V}$ \\
\hline & & Penghawaan & $\mathrm{V}$ \\
\hline & Legibilitas & Signage & - \\
\hline & & Pemandangan & $\mathrm{V}$ \\
\hline & & Vegetasi & $\mathrm{V}$ \\
\hline \multirow{5}{*}{ Aktivitas } & Formal & Kuliah & - \\
\hline & & Diskusi & $\mathrm{V}$ \\
\hline & Informal & $\begin{array}{l}\text { Kegiatan } \\
\text { Himpunan }\end{array}$ & $\mathrm{V}$ \\
\hline & & $\begin{array}{l}\text { Makan dan } \\
\text { minum }\end{array}$ & $\mathrm{V}$ \\
\hline & & Ngobrol & $\mathrm{V}$ \\
\hline \multirow{6}{*}{ Makna } & Aman & Terbuka & $\mathrm{V}$ \\
\hline & & Terlindung & - \\
\hline & Nyaman & Sejuk & $\mathrm{V}$ \\
\hline & & Tenang & - \\
\hline & Fungsi & $\begin{array}{l}\text { Fasilitas } \\
\text { sesuai }\end{array}$ & - \\
\hline & & $\begin{array}{l}\text { Kejelasan } \\
\text { fungsi }\end{array}$ & $\mathrm{V}$ \\
\hline
\end{tabular}

Area meja batu memenuhi 14 indikator kebetahan $(63,6 \%)$ terhadap ruang, (lihat tabel 5) sehingga responden 
memilih selasar sebagai area yang memiliki tingkat kebetahan keempat tertinggi.

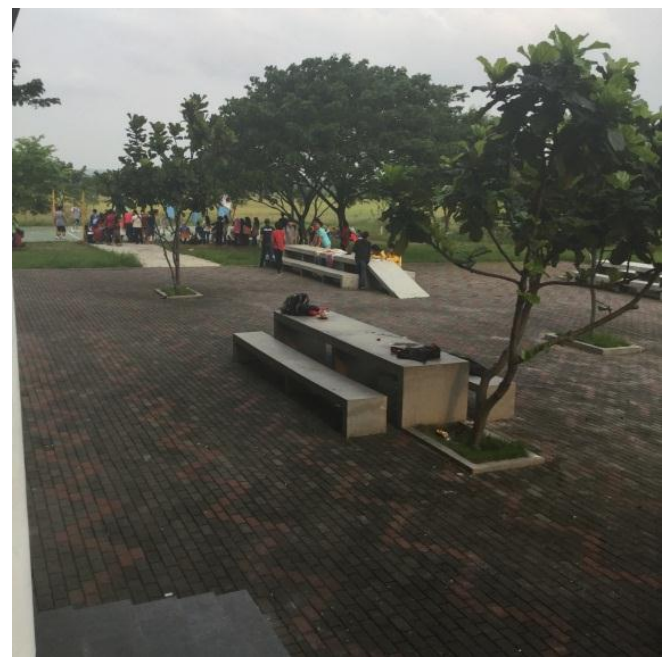

Gambar 5. Area meja batu

Sumber: Dokumentasi penulis, 2016

Kondisi area favorit mahasiswa merupakan area yang selalu dipenuhi oleh mahasiswa dari berbagai jurusan. Bila data di atas dikaitkan dengan alasan mengapa tempat tersebut menjadi area favorit, maka responden cenderung memilih area yang nyaman dijadikan sebagai tempat belajar dan beraktivitas (33 responden), area yang bisa bersosialisasi dengan baik (17 responden) dan memiliki penghawaan yang baik (sejuk, dingin) (9 responden) (lihat diagram 6).

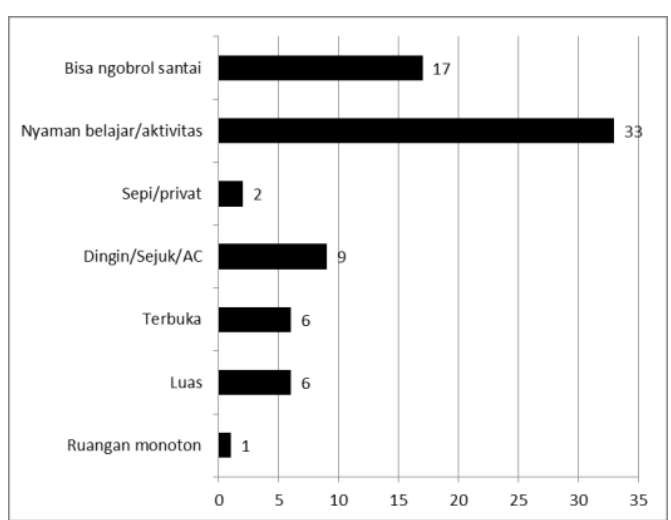

Diagram 6. Frekuensi alasan menjadi area favorit dalam kampus
Dari hasil tersebut bila dibandingkan dengan pemilihan area favorit dalam kampus maka ruang kelas, kantin, selasar dan meja batu memenuhi kriteria alasan menjadi area favorit karena area-area tersebut dapat berfungsi sebagai tempat belajar, dapat digunakan untuk bersosialisasi sesama mahasiswa, dan memiliki suhu udara yang baik.

Hasil tersebut akan dijadikan sebagai kata kunci untuk mengidentifikasi alasan mahasiswa merasa betah berada di dalam lingkungan kampus.

\section{Kategori Kata Kunci Kebetahan}

Dari hasil frekuensi alasan area favorit, selanjutnya dilakukan pengkategorian kata kunci berdasarkan kedekatan makna kata yang serupa/sama (lihat tabel 6). Terdapat 2 buah kategori utama yang disebutkan oleh responden, kategori pertama adalah sifat ruang yang diwakili oleh sepi/privat, dingin/sejuk, terbuka, luas dan monoton dengan jumlah 24 frekuensi. Kategori kedua adalah aktivitas yang dilakukan, yang diwakili oleh bisa ngobrol santai dan nyaman belajar/beraktivitas dengan jumlah 50 frekuensi.

Tabel 6. Kategori kata kunci alasan memilih area favorit dalam kampus

\begin{tabular}{|c|c|}
\hline Kata Kunci & $\begin{array}{l}\text { Kata/Frase } \\
\text { diwakili }\end{array}$ \\
\hline \multirow{5}{*}{ Sifat Ruang } & Sepi/privat (2) \\
\hline & Dingin/sejuk (9) \\
\hline & Terbuka (6) \\
\hline & Luas (6) \\
\hline & Monoton (1) \\
\hline \multirow{2}{*}{$\begin{array}{l}\text { Aktivitas yang } \\
\text { dilakukan }\end{array}$} & $\begin{array}{l}\text { Bisa ngobrol santai } \\
(17)\end{array}$ \\
\hline & $\begin{array}{l}\text { Nyaman belajar/ } \\
\text { beraktivitas (33) }\end{array}$ \\
\hline
\end{tabular}

Dari hasil tersebut dapat disimpulkan bahwa area yang dipilih oleh mahasiswa ITSB sebagai area favorit adalah area yang dapat digunakan 
untuk belajar dan beraktivitas dengan nyaman serta dapat mengobrol santai tanpa terganggu. Area favorit ini dapat dikaitkan dengan faktor kebetahan mahasiswa terhadap ruang.

\section{Tingkat Kebetahan Mahasiswa Terhadap Lingkungan Kampus ITSB}

Berdasarkan data mengenai tingkat kebetahan mahasiswa terhadap lingkungan Kampus ITSB secara umum maka dihasilkan $72 \% \quad$ (43 responden) mahasiswa merasa betah terhadap kondisi lingkungan Kampus ITSB saat ini, sedangkan 28\% (16 responden) mahasiswa merasa tidak betah (lihat diagram 7).

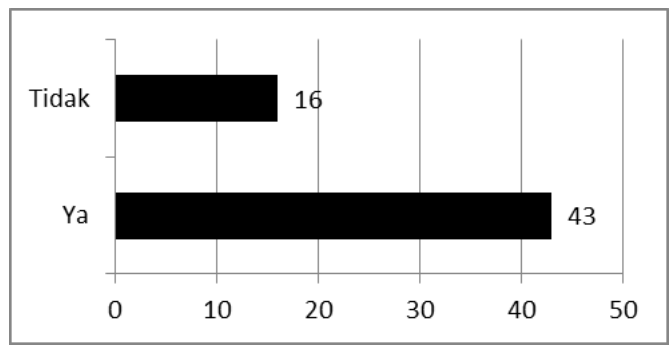

Diagram 7. Frekuensi kebetahan terhadap lingkungan kampus

Dengan frekuensi kebetahan yang cukup tinggi, alasan mahasiswa merasa betah di dalam kampus berdasarkan hasil open coding diperoleh 12 kata kunci dengan total frekuensi 74 (lihat diagram 8). Kata kunci yang paling banyak muncul adalah karena ada teman (15 responden), kegiatan (11 responden), fasilitas yang cukup baik (11 responden), banyak pohon (11 responden), internet (11 responden), banyak ruangan (6 responden), AC (2 responden), tempat teduh (2 responden), dosen baik ( 2 responden), listrik (1 responden), area bersih (1 responden), terpaksa (1 responden).

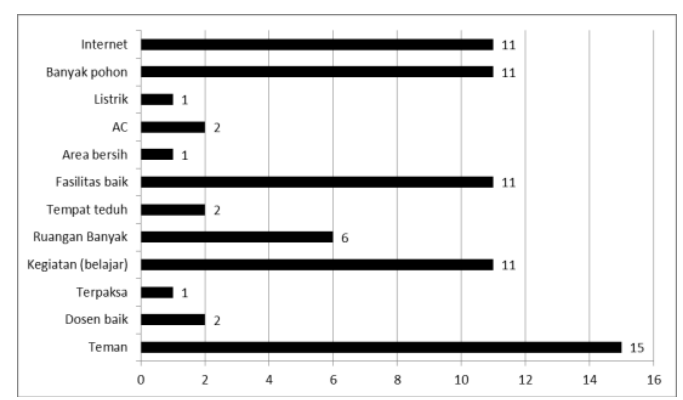

Diagram 8. Frekuensi kata kunci alasan mahasiswa merasa betah di dalam kampus

Dari hasil frekuensi alasan kebetahan dalam kampus, selanjutnya dilakukan pengkategorian kata kunci berdasarkan kedekatan makna kata yang serupa/sama (lihat tabel 7). Terdapat 3 buah kategori utama yang disebutkan oleh responden, kategori pertama adalah interaksi dengan pengguna lain yang diwakili oleh dosen baik dan teman dengan jumlah 17 frekuensi. Kategori kedua adalah ruang dan fasilitas, yang diwakili oleh internet, banyak pohon, listrik, AC, area bersih, fasilitas baik, tempat teduh dan ruangan banyak dengan jumlah 45 frekuensi. Kategori ketiga adalah aktivitas yang dilakukan, yang diwakili oleh belajar dan terpaksa dengan jumlah frekuensi 12 .

Tabel 7. Kategori kata kunci alasan kebetahan di dalam kampus

\begin{tabular}{ll}
\hline Kata Kunci & $\begin{array}{l}\text { Kata/Frase } \\
\text { diwakili }\end{array}$ \\
\hline $\begin{array}{l}\text { Interaksi dengan } \\
\text { pengguna lain (sosial) }\end{array}$ & Dosen baik (2) \\
\cline { 2 - 2 } & Teman (15) \\
\hline & Internet (11) \\
\cline { 2 - 2 } $\begin{array}{l}\text { Banyak pohon (11) } \\
\text { Ruang dan fasilitas }\end{array}$ & Listrik (1) \\
\cline { 2 - 2 } & AC (2) \\
\cline { 2 - 2 } & Area bersih (1) \\
\cline { 2 - 2 } & Tesilitas baik (11) \\
\cline { 2 - 2 } & Ruangan teduh (2) banyak (6) \\
\hline $\begin{array}{l}\text { Aktivitas yang } \\
\text { dilakukan }\end{array}$ & Belajar (11) \\
\hline
\end{tabular}

Dari hasil tersebut dapat disimpulkan bahwa mahasiswa ITSB akan merasa 
betah terhadap ruang/area yang memiliki kondisi ruang dan fasilitas yang baik. Bila kondisi ruang sudah baik maka akan membangun interaksi sosial yang baik dengan pengguna lain. . Bila melihat hasil sebelumnya maka ruang-ruang yang dimaksud adalah ruang kelas, kantin, selasar dan meja batu, dimana ketiganya dapat digunakan dengan fungsi yang beragam (multifungsi).

\section{Kesimpulan}

Dari hasil penelitian yang telah dilakukan maka dapat disimpulkan bahwa kebetahan mahasiswa terhadap sebuah ruang/lingkungan dalam kampus dapat disebabkan oleh tiga kriteria, yaitu interaksi pengguna lain (sosial), ruang dan fasilitas (fisik) dan aktivitas yang dilakukan di dalam kampus. Pengguna lain yang dimaksud dalam penelitian ini adalah mahasiswa dan dosen, ruang dan fasilitas yang dimaksud adalah ruang-ruang serta fasilitas fisik yang mendukung, dan yang termasuk aktivitas yang dilakukan adalah kegiatan formal (kuliah, bimbingan) dan informal (unit, himpunan). Ruang dan fasilitas fisik menjadi faktor utama yang berkaitan dengan kebetahan. Indikator ruang yang memiliki tingkat kebetahan yang tinggi adalah ruang yang cenderung terbuka, memiliki penghawaan yang baik dan dapat menampung berbagai aktivitas. Bila ketiga kriteria ini dapat dipenuhi dengan baik maka akan mampu menghasilkan sebuah ruang/area yang nyaman bagi penggunanya.

Penelitian ini merupakan penelitian dasar dan sederhana yang masih memiliki peluang untuk dikembangkan lebih lanjut terkait dengan substitusi subyek penelitian, misalnya dosen atau karyawan, untuk melihat kebetahan dari sudut pandang pengguna yang berbeda. Selain itu eksekusi dan perbaikan desain terhadap masukan hasil penelitian ini juga perlu dan sangat memungkinkan untuk dilakukan demi terciptanya lingkungan kampus yang kondusif agar pengguna dapat merasa nyaman dan betah beraktivitas di dalamnya.

\section{Daftar Pustaka}

Altman, I \& Low, S. (1992). Place Attachment. New York: Plenum Press

Blesser, B \& Salter, L. (2009). Spaces Speak, Are You Listening?. London: The Mit Press

Creswell, J.W. (2008). Research Design: Qualitative, Quantitative, and Mixed Methods Approaches. California: Sage Publications, Inc.

Farasa, Nisa \& Kusuma, H. (2015). Faktor-faktor yang Mempengaruhi Kebetahan di Kafe: Perbedaan Preferensi Gender dan Motivasi. Prosiding Temu Ilmiah IPLBI.

Groat, L. \& Wang, D. (2002). Architectural Research Methods. New York: John Wiley \& Sons. Inc.

Kumar, Ranjit. (2005). Research Methodology, A Step by Step Guide for Beginner. London: Sage Publications.

Lynch, K. (1960). The Image of The City. United States : Twentieth Printime.

Montgomery, J. (1998). Making a City: Urbanity, Vitality and Urban Design. Journal of Urban Design 3 (1), p 93-116.

Oldenburg, R. (1997). The Great Good Place. Cambridge: Da Capo Press.

Rachman, R \& Kusuma, H. (2014). Definisi Kebetahan dalam Ranah 
Arsitektur dan Lingkungan

Perilaku. Bandung: Jurnal IPLBI.

Ujang, Norsidah. (2010). Place

Attachment and Continuity of

Urban Place Identity. Asian

Journal of Environtment-

Behaviour Studies. 
Jurnal Teknik Arsitektur ARTEKS, Volume. 2, Nomor 1, Desember 2017 ISSN 2541-0598 